\title{
Practical considerations informing teachers' technology integration decisions: the case of tablet PCs
}

\author{
Natalie Pareja Roblin, Jo Tondeur, Joke Voogt, Bram Bruggeman, Griet \\ Mathieu \& Johan van Braak
}

To cite this article: Natalie Pareja Roblin, Jo Tondeur, Joke Voogt, Bram Bruggeman, Griet Mathieu \& Johan van Braak (2018): Practical considerations informing teachers' technology integration decisions: the case of tablet PCs, Technology, Pedagogy and Education

To link to this article: https://doi.org/10.1080/1475939X.2017.1414714

曲 Published online: 05 Jan 2018.

Submit your article to this journal ๘

Q View related articles $\sqsubset$

View Crossmark data ־ 


\title{
Practical considerations informing teachers' technology integration decisions: the case of tablet PCs
}

\author{
Natalie Pareja Roblinn ${ }^{\mathrm{a}, \mathrm{b}}$ (D), Jo Tondeura, (D), Joke Voogt ${ }^{\mathrm{d}, e}$ (D), Bram Bruggeman ${ }^{\mathrm{a}}$, \\ Griet Mathieu ${ }^{f}$ and Johan van Braak ${ }^{\mathrm{a}}$ iD
}

aDepartment of Educational Studies, Ghent University, Ghent, Belgium; 'bearning Research and Development Center, University of Pittsburgh, Pittsburgh, PA, USA; 'Department of Teacher Education, Vrije Universiteit Brussel, Brussels, Belgium; ${ }^{d}$ College of Child Development and Education, University of Amsterdam, Amsterdam, the Netherlands; eDepartment of Teacher Education, Windesheim University of Applied Sciences, Zwolle, the Netherlands; ${ }^{\mathrm{f} C e n t e r}$ for Adult Education Het Perspectief, Ghent, Belgium

\begin{abstract}
The unique characteristics of tablet PCs promise important benefits for education. Yet, little is known about the rationale underlying teachers' decisions concerning their educational uses within the constraints of daily classroom practice. The current multiple case study investigated the practical considerations informing nine secondary school teachers' decision-making processes regarding the use of tablet PCs. Stimulated recall interviews revealed 10 criteria underpinning teachers' instructional decisions. Four criteria influenced the degree of congruence with teachers' previous practices: familiarity, alignment with course content, opportunities to achieve (new) instructional goals efficiently, and compatibility with established pedagogical beliefs. Costs and benefits of tablet PCs were determined in terms of educational added value, lesson preparation requirements and potential disruptions to the learning environment. Finally, access to a solid technology infrastructure, supportive school policies and knowledge of how to effectively integrate tablet PCs with course content were identified as important pre-conditions for sustainable implementation. Overall, the results suggest that practical concerns constitute a critical element in teachers' decision making, influencing not only teachers' intention to adopt tablet PCs, but also the ways in which they use this technology to support instruction.
\end{abstract}

\section{ARTICLE HISTORY}

Received 21 August 2016

Accepted 13 May 2017

\section{KEYWORDS}

Tablet PCs; mobile technology; technology integration; teacher decision making

\section{Introduction}

Increasing access to mobile devices such as tablet PCs (hereafter tablets) presents ample opportunities to enhance teaching and learning by providing gateways to a broad range of learning and collaboration resources (Johnson et al., 2013). Haßler, Major, and Hennessy (2015) identified several affordances specific to tablets, such as the integration of multiple features within one device, easy customisation and portability. These features allow for the use of tablets in versatile and non-obtrusive ways, and provide multiple opportunities to contribute to student-centred learning and to more differentiated forms of instruction (Ifenthaler \& Schweinbenz, 2013; Looi et al., 2009; Moran, Hawkes, \& El-Gayar, 2010).

The growing popularity of tablets is leading to a rapid uptake in education. In a review of initiatives related to the use of tablets in education, Tamim, Borokhovski, Pickup, and Bernard (2015) found that 
a growing number of countries are embarking on large-scale, government-supported initiatives to distribute tablet devices to schools. Interestingly, their review also revealed that most of these initiatives were driven by 'tablet hype' rather than by educational frameworks or research-based evidence. In fact, research on the educational uses and benefits of tablets is relatively new. So far, research efforts have targeted students' expectations of and attitudes towards the use of tablets (e.g. Courtois et al., 2014; Dündar \& Akçayır, 2014; El-Gayar, Moran, \& Hawkes, 2011), and the potential contributions of tablets to improve student learning and motivation (e.g. Ciampa, 2014; Enriquez, 2010; Li, Pow, Wong, \& Fung, 2010). By contrast, teachers' perspectives with regard to the educational uses of tablets have received much less attention (cf. Gómez \& Badia, 2016; Ifenthaler \& Schweinbenz, 2013; Montrieux, Vanderlinde, Curtois, Schellens, \& De Marez, 2014).

Given the increasing investments in the acquisition of tablets made by schools around the world and the limited research evidence available to guide these initiatives, more research about the use of tablets in education is warranted. One major issue relates to teachers' decisions about whether to integrate tablets and how. Previous studies investigating teachers' technology integration decisions suggest that these are largely informed by practical concerns, such as access to technology in the school, how comfortable teachers and students feel with a particular technology, or the time and effort that would need to be invested to prepare and enact a lesson (e.g. Boschman, McKenney, \& Voogt, 2014; Graham, Borup, \& Sith, 2012; Greenhow, Dexter, \& Hughes, 2008; Oncu, Delialioglu, \& Brown, 2008). Building on this body of work, the current study aims at understanding the practical considerations mediating teachers' instructional decisions pertaining to the integration of tablets. More specifically, we describe a multiple case study involving nine secondary school teachers who used tablets to support classroom instruction. Using the 'practicality ethic' (Doyle \& Ponder, 1978) described below as a general analytic framework, we examine the criteria teachers used to judge the practicality of tablets, thereby making visible the reasoning process underlying their instructional decisions. By providing in-depth insights into teachers' decision making, our findings contribute to the emerging literature about the use of tablets in education as well as to the general literature on teacher technology integration decisions.

\section{Theoretical framework}

\section{Teachers' technology adoption decisions}

Several models and theories aim to capture the processes underlying an individual's decision to adopt an innovation, such as a new technology (for an overview, see Straub, 2009). Below we outline some of these models, ultimately converging to the model that is at the core of the current study.

A well-known model specifically developed to answer questions about technology adoption is the Technology Acceptance Model (TAM). This model posits that users' acceptance of a new technology is determined by two key dimensions, namely'ease of use' and 'perceived usefulness' (Venkatesh, Morris, Davis, \& Davis, 2003). Although the TAM has been widely applied to investigate technology adoption across many fields, it has also been criticised for being too simplistic (Chang, Lieu, Liang, Liu, \& Wong, 2012) and for not acknowledging individual differences that may influence one's intention to use a new technology (Straub, 2009).

Building on the TAM and other existing models concerned with technology adoption and use, Venkatesh and colleagues (2003) developed the Unified Theory of Acceptance and Use of Technology (UTAUT). This theory identifies performance expectancy, effort expectancy, social influence and facilitating conditions as key determinants of usage behaviours. The UTAUT also takes into account individual differences, thereby addressing some of the limitations of its predecessor. Yet, critics suggest that both the TAM and the UTAUT fail to capture normative influences specific to the context of educational organisations, such as the potential influence of a technology on the relationships with students (Straub, 2009).

In the field of educational change, the Concerns-Based Adoption Model (CBAM) is widely used. The CBAM aims at measuring, describing and explaining the process of change experienced by teachers 
involved in attempts to implement new curriculum materials and instructional practices (Anderson, 1997). It consists of three diagnostic dimensions that represent key aspects of the change process as it is experienced by teachers (Hall \& Hord, 1987). A first dimension, the stages of concern, describes how teachers perceive an innovation and how they feel about it at different points in its implementation. The other two dimensions provide a framework for understanding general patterns of teacher behaviour pertaining to the extent to which they use (i.e. levels of use) and modify (i.e. innovation configurations) the innovation (Hall \& Hord, 1987). Together, the three dimensions of the CBAM contribute to understanding how individual concerns can influence adoption decisions. However, one limitation of this model is that it assumes that teachers will be inherently resistant to change, thereby ignoring individual teachers' possible preferences for an innovation (Straub, 2009), and how these may influence their adoption decisions.

Finally, another model rooted in educational change theories and in an ecological approach to teacher behaviour is the practicality ethic (Doyle \& Ponder, 1978; Janssen, Westbroek, Doyle, \& van Driel, 2013). The practicality ethic offers useful interpretative tools for understanding how teachers make decisions and how they respond to external influences that affect their established habits and practices (Janssen et al., 2013). The main assumption behind this framework is that teachers' decisions are largely guided by a practical rationality, which can be defined as a set of principles or values practitioners use to justify or otherwise discard actions in an instructional situation (Herbst, Nachlieli, \& Chazan, 2011). From this perspective, it is anticipated that teachers will be likely to adopt a new technology only once they perceive it as 'practical', or in other words, once they acknowledge its feasibility and benefits within the multiple constraints of daily classroom practice.

Various studies have shown that teachers' technology integration decisions are largely influenced by a practicality ethic. For example, Harris and Hofer (2011) investigated the decisions made by experienced teachers as they engaged in technology-enriched instructional planning. Their findings reveal that teachers' decisions were first driven by considerations about the content they had to teach. Once this 'content imperative' was satisfied, teachers' decisions about technology integration mainly revolved around strategic choices specific to the classroom context, such as time available to cover the curriculum that needs to be taught, access to technology resources in the school and other contextual constraints. Similarly, Boschman et al. (2014) found that teachers' decisions about the design of a technology-rich learning environment were largely informed by practical concerns regarding the feasibility of a particular technology use in relation to classroom practice.

\section{Dimensions of the practicality ethic in teacher decision making}

Doyle and Ponder (1978) highlighted three main dimensions of the practicality ethic: congruence, costs and instrumentality. The authors contended that, taken together, these three dimensions characterise the various 'rules of thumb' teachers use to judge whether a proposed change may qualify as practical or not. The congruence dimension refers to the extent to which the proposed change aligns with teachers' current practices, core values and pedagogical beliefs (Doyle \& Ponder, 1978). Changes that diverge largely from what teachers would typically do in their teaching practice are often characterised as impractical, and therefore are less likely to be implemented in the classroom. Likewise, teachers will tend to resist changes that are dissonant with their pedagogical beliefs and core values (Zhao, Pugh, Sheldon, \& Byers, 2002). In fact, research suggests that teachers' pedagogical beliefs can be a strong predictor of their technology uses (Ertmer, 2005; Ottenbreit-Leftwich, Glazewski, Newby, \& Ertmer, 2010). If teachers perceive that technology addresses important instructional and learning needs, the perceived value will be higher and subsequent use more likely (Chang et al., 2012). Next to alignment with teachers' pedagogical beliefs and regular practice, Zhao and colleagues (2002) identified a third area where the notion of congruence might be of importance, namely the degree to which an innovation deviates from the dominant set of values, pedagogical beliefs and practices of teachers and administrators in a school. Various studies indicate that the school culture can indeed play an important role in teachers' technology integration decisions (cf. de Koster, Kuiper, \& Volman, 2012). 
The second dimension refers to the relationship between the costs required to enact a proposed change and the benefits a teacher might expect from it. Teachers will be likely to adopt a change when its perceived benefits potentially outweigh the perceived investment required to implement it. The cost dimension involves judgements about time and effort, social costs and rewards, and potential risks associated with the enactment of the proposed change (Ponder \& Doyle, 1977). The integration of a new technology often requires additional time and effort from teachers (Lai \& Chen, 2011). For instance, teachers will need to plan activities that are suitable for the technology, verify that the software is available in the school and prepare for eventual technical problems. All of these represent an extra load to the already busy schedule of a teacher. Social costs refer to reactions from students, parents, colleagues and/or school leaders, and their consequent impact on the image and status of the teacher. A teacher might, for example, be resistant to integrate a new technology if she or he fears that it could bring into question her/his authority or knowledge in front of students. Finally, perceived risks associated with the enactment of a proposed change have an important influence on teachers' judgements about its practicality. If the risks of failure are perceived as too high, teachers will not be willing to engage in new pedagogical practices (Fevre, 2014). In fact, even if teachers regard the use of a new technology as effective and congruent with their core values, they may still choose not to integrate it if they feel it might jeopardise other goals regarded as important (Zhao \& Cziko, 2001).

The third and last dimension, instrumentality, refers to the extent to which the innovation is clear and provides concrete referents and means to implement it amongst the contingencies of classroom practice (Doyle \& Ponder, 1978). Practical examples of technology integration in the classroom (e.g. Tondeur, Pareja Roblin, van Braak, Fisser, \& Voogt, 2013), professional development programmes aiming at facilitating teacher understanding of how technology can be used in ways that enhance teaching and learning (e.g. Twining, Raffaghelli, Albion, \& Knezek, 2013), along with school technology integration policies (e.g. Vanderlinde, van Braak, \& Tondeur, 2010), can contribute to clarifying the purposes and potential benefits of technology integration. But this alone is not enough to influence teachers' decision to embrace technology. Teachers also need to be sure that they will have (easy) access to the necessary resources and human support (Zhao et al., 2002).

The three dimensions of the practicality ethic are not independent but rather interact with each other. For example, the extent to which a new technology is congruent with teachers' pedagogical beliefs and previous practice influences the perceived costs and risks associated with its curricular integration. Similarly, instrumentality (e.g. access to resources and support in the school) will determine to a large extent the perceived costs of using a new technology as well as the degree to which its integration is likely to be congruent with the existing school culture.

\section{Purpose of this study}

Given the high expectations for the use of tablets in education, research that explores the reasoning behind teachers' instructional decisions pertaining to its curricular integration is of paramount importance to guide future professional development efforts and school policies. The ultimate goal of the current study is to understand the practical considerations underpinning teachers' decisions about the integration of tablets. The practicality ethic described before was used as a general analytical framework. The following research question guided the study: What practical considerations (in terms of congruence, cost-benefit relationships and instrumentality) mediate teachers' decisions about the integration of tablets in their teaching practice?

\section{Method}

A multiple case-study approach (Yin, 2003) was adopted, in which each teacher constituted a case and the schools were defined as the context. The cases were bound to teachers' instructional uses of tablets and to the practical concerns informing these uses. Nine teachers from three technical and vocational secondary schools in Flanders (Belgium) participated in this study. 


\section{Study context}

Participating teachers were involved in a pilot project aimed at exploring the potential benefits of tablets in the context of technical and vocational education. Research suggests that, next to suffering from a negative image, technical and vocational school students tend to perform worse and are more prone to dropping out of school (Van Houtte \& Stevens, 2010). The pilot project described here was part of a larger effort to address these problems by increasing student motivation and engagement through the integration of new technologies.

As part of this pilot project, two technical schools and one vocational school received 16 tablets for a period of three to four weeks (see Table 1 for an overview of school characteristics). Schools were free to determine how and to what extent they would use tablets to support classroom instruction, resulting in various approaches to implementation. Whereas schools 1 and 2 decided that tablets would be used by one class only, school 3 chose to use tablets in different classes and grade levels. At the moment the project started, none of the three schools had a clear vision or policy plan pertaining to the implementation of tablets. The pilot project was seen by strategic leaders as an opportunity to develop an understanding of the educational affordances of tablets which could later inform its school-wide implementation.

\section{Participants}

Teacher age varied considerably, ranging from 33 to 60 years old. Teaching experience also varied, although most teachers had more than 10 years of experience in the classroom (see Table 2). Teachers from schools 1 and 2 were all female and taught general subjects (e.g. history, mathematics) whereas teachers from school 3 were all male and taught primarily technical subjects (e.g. electricity). All teachers had previously used technology to support classroom instruction, but this was the first time they used tablets.

Before the start of the project, all teachers participated in a half-day workshop about tablets and educational applications (apps). During this workshop, teachers had the opportunity to see examples

Table 1. School characteristics.

\begin{tabular}{llll}
\hline & \multicolumn{1}{c}{ School 1 } & \multicolumn{1}{c}{ School 2 } & \multicolumn{1}{c}{ School 3 } \\
\hline Type of school & Technical & Technical & Vocational \\
Total no. of students & 414 & 720 & 500 \\
Total no. of teachers & 75 & 120 & 100 \\
Classes involved in the study & & & \\
Grade level & Grade 12 & Grade 11 & Grade 10 through 12 \\
Specialisation & Public relations & Technical sciences & Auto motors \\
Number of students per class & 9 & 9 & 12 (Grade 10) \\
& & & 6 (Grade 11) \\
& & & 14 (Grade 12) \\
\hline
\end{tabular}

Table 2. Characteristics of the participants involved in the study.

\begin{tabular}{|c|c|c|c|c|}
\hline & Teacher & Subject domain & $\begin{array}{c}\text { Teaching experience (in } \\
\text { years) }\end{array}$ & \# lessons taught with tablets \\
\hline \multirow[t]{3}{*}{ School 1} & Karen & History & 8 & 3 \\
\hline & Laura & Literacy & 26 & 1 \\
\hline & Susan & Public relations & 17 & 1 \\
\hline \multirow[t]{3}{*}{ School 2} & Valerie & Literacy & 11 & 5 \\
\hline & Martha & History & 32 & 3 \\
\hline & Melanie & Mathematics; technical design & 25 & 3 \\
\hline \multirow[t]{3}{*}{ School 3} & Walter & Electricity; bikes \& motors & 5 & 4 \\
\hline & Felix & Bikes & 4 & 2 \\
\hline & Bert & French & 28 & $3^{*}$ \\
\hline
\end{tabular}

\footnotetext{
*The same lesson was taught to three different groups of students.
} 
of generic apps they could use to support classroom instruction. On-site support was provided by the schools' technology coordinators, who played a pivotal role in ensuring Internet access, solving technical difficulties and assisting teachers with searching and installing apps.

\section{Data collection}

Data were collected by means of stimulated recall interviews supported by classroom observations. The goal of classroom observations was twofold. First, they contributed to gaining insight about the ways in which teachers used tablets, thereby serving as primary input for the recall interviews and providing a context for understanding teachers' instructional decisions. Second, observations served as means for triangulation by enabling the researchers to corroborate information gathered from interviews. Observations were based on a semi-structured template where researchers registered information about the ways in which tablets were used in the lesson (e.g. amount of time dedicated to the use of tablets, apps used, teacher and student roles). The number of observations per teacher varied depending on lesson schedules and teacher availability, but each teacher was observed at least once.

The goal of stimulated recall interviews was to gather information about the rationale underlying teachers' instructional decisions about the use of tablets and, more specifically, the practical considerations mediating these decisions. Stimulated recall interviews are a powerful method to elicit teachers' thought processes and the values that drive their actions through the use of videos, photographs and other types of prompts aimed at jogging teachers' memories of an event (Calderhead, 2011). In the current study, pictures accompanied by short descriptions of the lessons observed were used to stimulate teacher recall. It is important to note that, while information gathered from lesson observations was used to trigger teachers' recall, interviews covered the full range of teachers' experiences with tablets.

Interview questions were semi-structured and focused on a number of themes that were common across all participants (e.g. reasons why tablets were used in specific ways, criteria to select apps, similarities with previous practice, time and effort invested in lesson preparation and enactment), as well as on unique instances observed during the lessons (e.g. reasons to use tablets outside the classroom). Interviews lasted between 60 to 90 minutes and were audio recorded and then transcribed for analysis.

\section{Data analysis}

Data analysis consisted of within- and cross-cases analyses, and followed a three-step procedure: data reduction, cross-case displays and conclusion drawing/verifying (Miles \& Huberman, 1994). In the data-reduction phase, observation records were used to generate short descriptions of the various ways in which teachers used tablets. Interview data were then analysed to identify the practical concerns guiding teachers' instructional decisions through a combination of deductive and inductive approaches (Fereday \& Muir-Cochrane, 2008). A codebook was developed using the core dimensions of the practicality ethic as general categories guiding data analysis. These general categories were subsequently further specified through inductive analyses of practical considerations related to each dimension of the practicality ethic (for an overview, see Table 3 ). This resulted in individual case descriptions that synthesised (1) the ways in which each teacher used tablets, and (2) concrete criteria within each dimension of the practicality ethic guiding teachers' decision-making processes.

In a second step, data from all individual cases were assembled and visually displayed in a matrix. This matrix provided a synthesis of the practicality criteria underlying individual teachers' decision-making processes (vertically) and facilitated comparison across cases (horizontally). The final step consisted of drawing and verifying conclusions. To make meaning of the data, three main tactics were used (Miles \& Huberman, 1994): (1) noticing patterns across cases; (2) clustering similar cases/criteria; and (3) making comparisons between cases. 


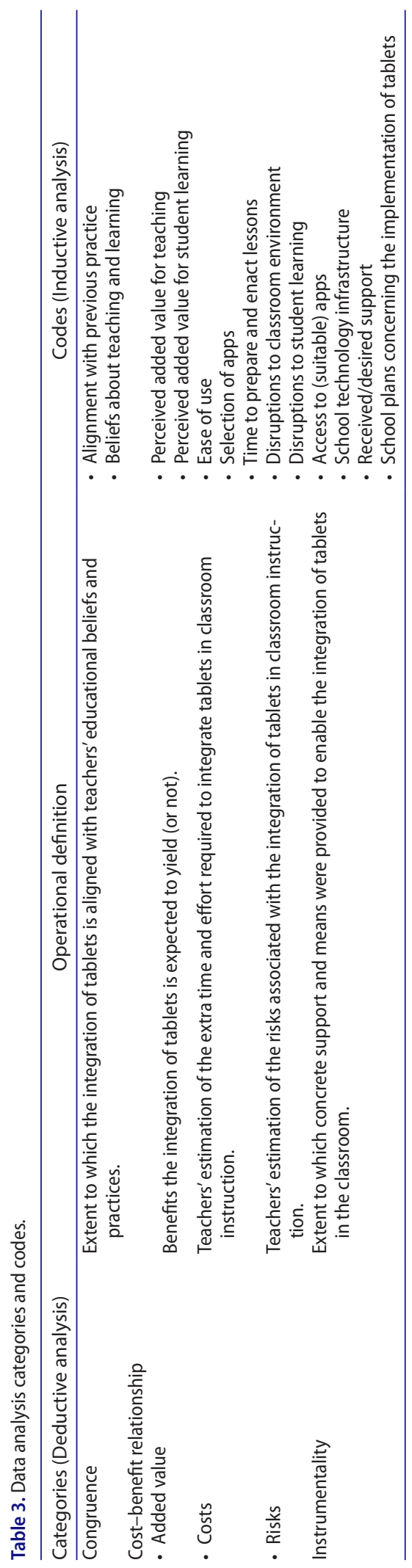




\section{Findings}

In the following sections, we discuss the practicality considerations mediating teachers' instructional decisions pertaining to the use of tablets. Findings are organised around the three dimensions of the practicality ethic described earlier.

\section{Congruence}

\section{Congruence with previous practice}

Table 4 illustrates the extent to which teachers' uses of tablets aligned with their previous teaching practice. As it is clear from this table, teachers' uses of tablets can be placed along a continuum ranging from uses that were reported to be very close to their previous practice to uses that departed away from what they would typically do.

Six out of nine teachers participating in the study used tablets both in ways that were highly congruent with their previous practice and that, to a greater or lesser extent, diverged from their usual practice. The remaining three teachers (Laura, Susan and Bert) used tablets only as a replacement for other (more familiar) technology. One main reason underlying teachers' decisions to use tablets in ways that were highly congruent with their previous practice was familiarity. Teachers purposely decided to propose activities they and their students already had experienced and/or felt comfortable with. This resulted in the selection of apps that were similar to the software they would typically use in the classroom (e.g. word processing, spreadsheets etc.).

The opportunity to achieve their current instructional goals more efficiently was the main rationale behind moderate levels of congruence with previous practice. Five teachers (Karen, Melanie, Valerie, Felix and Walter) explicitly decided to integrate tablets in lessons where their previous technology uses could be enhanced by the affordances of tablets. Instead of serving as a mere replacement of other technology, these teachers purposely used tablets to add an extra value to their previous practice. Finally, low levels of congruence were observed in four teachers (Valerie, Martha, Felix and Karen) who decided to use tablets to try out learning activities they already had in mind, but were not yet able to implement in the classroom. This indicates that these teachers saw the use of tablets as an opportunity to achieve new instructional goals.

Beyond familiarity and the opportunities to achieve (new) instructional goals more efficiently, fit with course content appears to have been a general rule of thumb guiding teachers' instructional decisions. Consequently, the selection of apps aligned with the content that needed to be taught influenced - and was often influenced by - the search for congruence with previous practice. Two strategies were commonly used by teachers to ensure content alignment. One strategy consisted of purposefully searching apps that would fit with their course content (Susan, Laura, Bert, Melanie). When unable to find the right 'fit', these teachers decided to settle for more generic apps that could replace other (more familiar) technologies. Another strategy consisted of reflecting upon the affordances of various apps and then exploring possible connections with the course content (Karen, Martha, Walter and Felix). The latter sometimes resulted in the discovery of apps that inspired new learning activities. Interestingly, one teacher (Valerie) commented how her way of thinking about the use of tablets changed as she started to let go of her typical lessons and explored the opportunities apps provide to address course content in different ways:

When the project started you think about your lessons and then you try to force the apps there, but later I did it the other way around. I looked at the apps and the things I wanted to teach and then [thought about] what I could do with these apps. Then it worked better. (Valerie)

\section{Congruence with pedagogical beliefs}

Teachers generally used tablets in ways that were compatible with their pedagogical beliefs and instructional goals. Constructivist pedagogical beliefs appear to have influenced the decision of three teachers (Walter, Felix and Karen) to use tablets in ways that supported problem solving, creativity and 

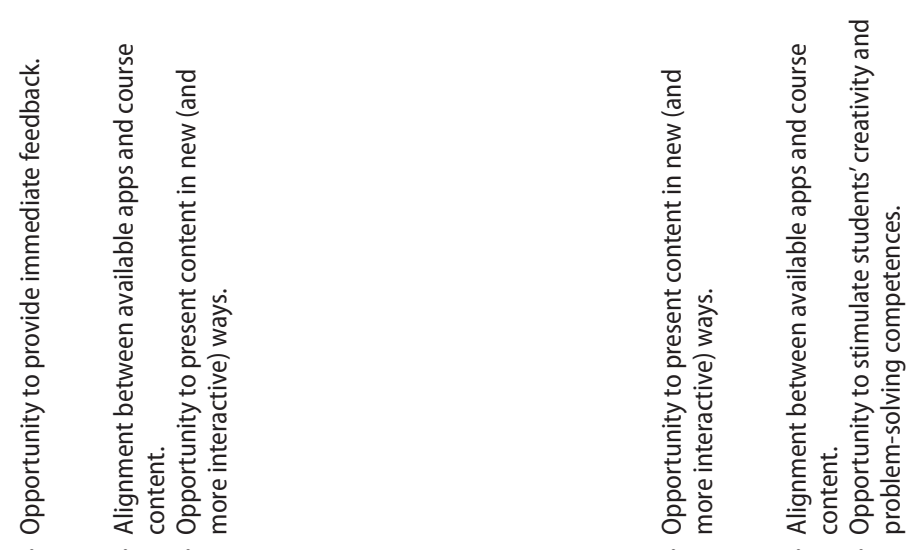

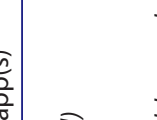

$\frac{2}{2}$

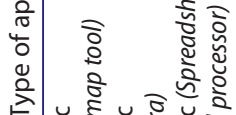

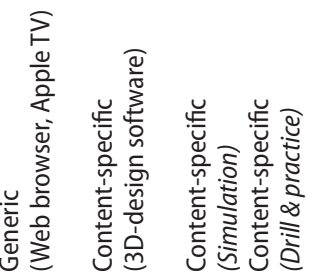

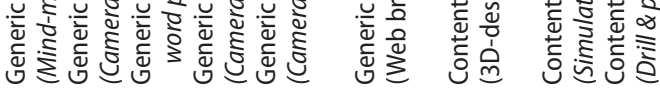

है

产

$\widehat{m}$

m

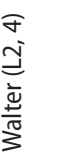

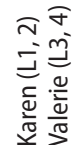

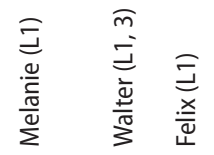

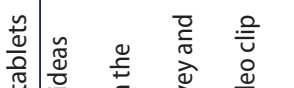

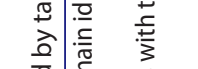

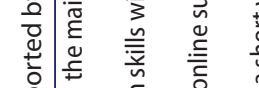

䒕

范产

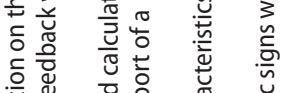

華苋

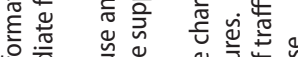

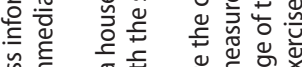

凹

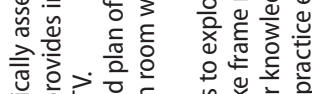

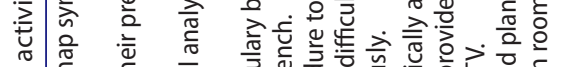

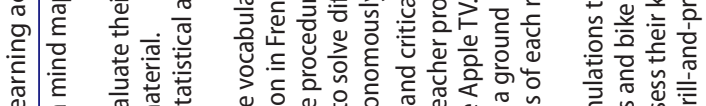

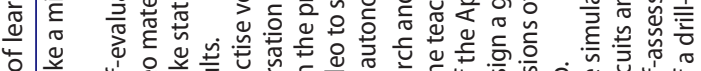

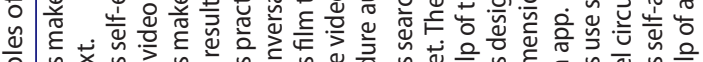

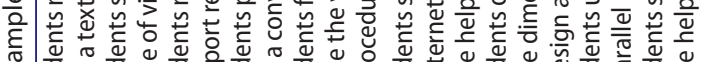

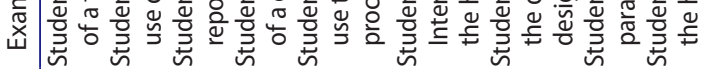

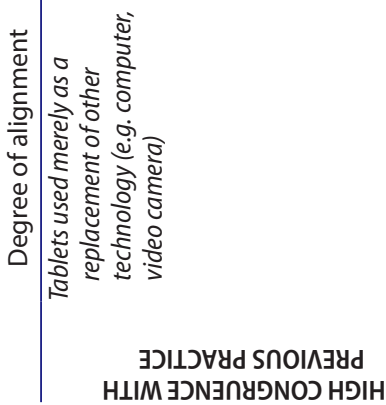

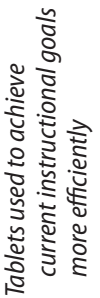

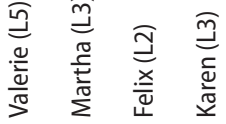
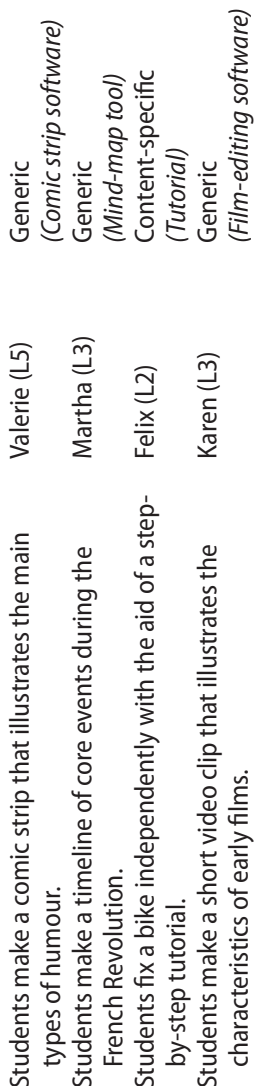

ֻับ

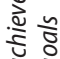

$\therefore$ 을

¿ू.

章.

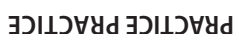

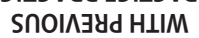

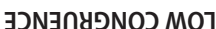


self-directed learning. For example, Walter believed that students learn best when they are actively engaged in learning, and therefore searched specifically for apps with interactive simulation features. Similarly, Karen and Felix saw the implementation of tablets as an opportunity to encourage students' problem solving and creativity, and planned learning activities that could support these types of competences. Felix explains:

As a teacher, I believe in the principle that students will learn better when they search for themselves [for solutions to problems], when they figure themselves out how to put all the pieces together. This is why I let them learn independently the procedure [to fix the bike] by following the instructions [on the tutorial].

Two teachers (Martha and Valerie) acknowledged that the use of tablets in the context of new learning activities challenged their beliefs about teaching and learning as well as their preferred forms of interaction with students. For example, Martha observed how part of her responsibility had to be transferred to students by no longer being able to control what information they had access to - something she could typically prevent in the past by using the digital board with the whole class. Similarly, Valerie commented how the use of tablets can put teachers in a position where students know almost as much as they do, thereby altering traditional forms of teacher-student interactions:

You are in a position in which you know almost as much as they - and I find that nice. This was a good class, but I can imagine that there are people that would not like it. I think that there are teachers who would hate that. (Valerie)

As will be discussed in the next section, the extent to which the use of tablets challenged teachers' pedagogical beliefs also appears to have an influence on how teachers assess the potential benefits and costs associated with its integration.

\section{Cost-benefit relationship}

The cost-benefit dimension refers to the extent to which teachers perceive that the benefits of integrating tablets in their teaching practice will outweigh the costs and risks associated with its use. This relationship is described below in the form of two main tensions emerging from the data.

\section{Added value for teaching vs lesson preparation time}

The availability of multiple tools within one device, and the opportunities these provide to present course content in more interactive and engaging ways, were highly valued by all teachers. Teachers also acknowledged that the versatility and portability of tablets contributed to a more efficient use of technology in the classroom. Nonetheless, teachers identified several requirements for the use of tablets to be fully efficient. For example, access to wireless Internet in the classroom had to be arranged. In addition, teachers had to reserve the devices in advance, verify that batteries were fully charged, make sure that all apps were installed and be prepared for possible technical contingencies. All these aspects demanded additional time and effort. Such organisational concerns were echoed by five out of nine teachers, and can be illustrated as follows:

I guess I am not confident enough with it, and I am afraid for where here in the school I have access to Internet. Then the effort is not [worth it]. I do not want to stand there and then find out that it does not work when you have planned your lesson around it. (Valerie)

Moreover, finding apps aligned with course content proved to be a challenging, time-consuming and often frustrating task for most teachers. One teacher explains:

Searching for apps, seeing what fits best with the course content, that was the most time consuming, the most difficult part. Once you have found something, then you can go on. But I think certain teachers, if they have to invest so much time into it, they will not do it. (Melanie)

\section{Added value for learning vs disruptions to the learning environment}

Opportunities to bring variation to the classroom through the introduction of multimedia resources were seen as a potential benefit of tablets. All teachers acknowledged that such variety could contribute to increasing student motivation and involvement. However, four teachers believed that this 
increase in motivation was due to the 'novelty effect' of tablets, and therefore would eventually wear off. In this respect, two teachers (Walter and Susan) affirmed that tablets would be more effective when used in combination with other resources (e.g. digital board, textbooks) and/or learning activities (e.g. hands-on activities).

Despite acknowledging some potential benefits, all teachers feared that tablets might significantly increase students' temptation to go off-task owing to the easy access to online games and social media. Aspects such as group size, grade level and group characteristics were associated with higher risks of student distraction and potential disruptive behaviour, particularly in the context of technical and vocational schools. Generally, teachers believed that the implementation of tablets would be challenging and impractical with large groups of students. Comments such as 'with large groups is not so evident', or 'I would not see myself able to keep them all under control', suggest that group size was indeed an important consideration underpinning teachers' decisions about the use of tablets. Teachers also stated that younger students and 'difficult groups' would be more vulnerable to the temptation of playing games, and would be therefore more difficult to 'keep under control'.

Beyond the concern for potential disruptions to the learning environment, teachers' scepticism concerning the added value of tablets to support student learning is striking. All teachers, except for Karen and Walter, questioned the extent to which the use of tablets could represent a real advantage over other technologies already used in the classroom. Comments such as 'I could do the same, or even better, on my digital board' (Martha), 'If I did it on paper it would have possibly had the same value and maybe it would have been faster' (Valerie), or 'it is nice to do but it does not really have an added value' (Bert), suggest that most teachers questioned whether and how tablets could be integrated in ways that truly enhance their instructional practices, and hence improve student learning.

\section{Instrumentality}

Teachers generally experienced tablets as user-friendly devices and felt that they, as well as their students, could quickly become familiar with them. However, teachers also acknowledged that the use of tablets, and particularly the selection of suitable apps for their subject domain, required additional knowledge and expertise from them. Six out of nine teachers indicated that, in order to harness its full educative potential, further professional development is needed about how to effectively integrate the use of tablets with course content.

In addition to the need for further professional development, access to continuous technical support in the school was considered an important criterion for the sustainable use of tablets. Throughout the pilot project, teachers received on-site support from technology coordinators who ensured access to the Internet and assisted teachers with the search and installation of apps. Such support was seen by six out of nine teachers as a pre-requisite for continuing the use of tablets. Access to a sufficient number of tablets was also an important consideration guiding teachers' instructional decision making. Five out of nine teachers stated that at least one tablet for every two students should be available. Teachers also shared their concern about how the use of tablets will be practically organised in the school, suggesting the importance of supportive organisational structures and procedures.

When asked about their school plans concerning the implementation of tablets, only teachers from school 2 acknowledged the intention of the school principal to buy additional tablets and encourage its use in cross-curricular project-based activities. All the other teachers reported to be unaware of concrete plans aimed at supporting its school-wide implementation.

\section{Discussion and conclusion}

The unique characteristics of tablets promise important benefits for education. Yet, little is known about the rationale underlying teachers' decisions concerning their educational uses (cf. Ifenthaler \& 
Schweinbenz, 2013; Montrieux et al., 2014). Such rationales ultimately determine the extent to which the potential benefits of tablets can be fully realised within the constraints of daily classroom practice. Using the practicality ethic (Doyle \& Ponder, 1978) as a general analytic framework, the current study identified 10 criteria underpinning teachers' instructional decisions about the use of tablets. As illustrated in Figure 1, all the practical concerns expressed by the teachers participating in the study fell within the three dimensions of the practicality ethic (i.e. congruence, cost-benefit relationships and instrumentality). In the next sections we discuss the criteria teachers used to inform their instructional decisions for each of these dimensions.

\section{Congruence}

Four criteria influenced the degree of congruence with teachers' previous practices. Alignment with course content, and hence access (or lack thereof) to apps that are suitable for the content to be taught, was a first criterion guiding teachers' decisions. This aligns with previous research showing that content often serves as an 'arbiter' in teachers' decision making about the adoption of technology tools in general (e.g. Harris \& Hofer, 2011), and tablets in particular (e.g. Ifenthaler \& Schweinbenz, 2013). Notably, access to apps aligned with course content sometimes inspired teachers to try out new learning activities. This suggests that teachers were willing to let go of their usual practices whenever able to find the 'right fit' between an app and the course content. However, finding this 'fit' was not always easy, in part because teachers were not fully aware of the range of apps available for their subject domain or of the types of learning activities that could be supported by tablets.

Familiarity with a particular task and/or technology application was another key criterion influencing the degree of congruence with teachers' previous practice. Our findings revealed that teachers were initially inclined to integrate tablets in the context of familiar activities, and only tended to depart from their usual practices once they had acquired more experience. Interestingly, teachers who taught (Susan, Laura) or designed (Bert) only one lesson integrated tablets in ways that were highly congruent with their previous practice. A possible explanation for this is that teachers often use their knowledge from past personal and professional experiences to inform their instructional choices (Connelly, Clandinin, \& Fang He, 1997). This knowledge is essential to anticipate potential classroom contingencies and ensure that instructional goals are successfully achieved (Janssen et al., 2013). The more familiar and comfortable teachers are with a particular learning activity and/or technology, the better equipped they are to make these predictions. This has important implications for future professional development and school initiatives, as it suggests the need for providing teachers with prolonged opportunities to experiment and become familiar with the educational uses of tablets.

The extent to which teachers perceived tablets as an opportunity to either achieve current goals more efficiently or to pursue new instructional goals was a third criterion influencing the degree of congruence with previous practice. Notably, uses that departed further away from typical practices were often inspired by an app and less by a purposeful pedagogical choice. Previous studies have also shown that many teachers use technology because it allows them to maintain their current goals more efficiently, rather than allowing them to do something completely new pedagogically (e.g. Harris \& Hofer, 2011; Zhao \& Cziko, 2001). Research on the use of tablets seems to corroborate these findings (Ifenthaler \& Schweinbenz, 2013; Li, 2010; Montrieux et al., 2014). The relatively limited drive to engage in new pedagogical practices could be explained by the inherent tension between teachers' practicality ethic on the one hand, and educational innovations on the other hand (Janssen et al., 2013). Professional development programmes should contribute to resolving this tension by providing concrete examples of how tablets can be integrated in ways that support new learning opportunities, yet attend to the constraints of daily classroom practice.

A fourth criterion influencing congruence relates to compatibility with teachers' pedagogical beliefs. The search for alignment with their established views about teaching and learning can prevent teachers from actively exploring the possibilities that tablets could offer to support other (more constructivist) instructional approaches (Ertmer, 2005). Some teachers felt that the use of tablets could challenge their 
pedagogical beliefs by moving away from teacher-centred instruction. This pushed them out of their comfort zone, bringing along a sense of high risk that could only be resolved once teachers perceived that letting go of what they value will potentially result in significant gains (Fevre, 2014). Interestingly, our findings suggest that some teachers did not perceive this as a risk worth taking. This brings us to the second dimension of the practicality ethic.

\section{Cost-benefit relationship}

Previous research suggests that teachers' technology integration decisions are largely influenced by the perceived added value of technology, that is, the extent to which teachers believe that a specific technology will allow them to improve the ways in which they teach, and thereby effectively facilitate student learning (e.g. Harris \& Hofer, 2011; McGrail, 2005). Like in the study of Ifenthaler and Schweinbenz (2013), our findings reveal the little confidence most teachers have in the benefits of tablets when compared to more familiar technologies. This is worrying, since failing to recognise clear added value substantially increases the risk that teachers ultimately decide to either reject the implementation of tablets or use them merely as a replacement for other technology, hence leaving the educational affordances of tablets underexploited.

Our findings also reveal a number of criteria teachers used to judge the costs and risks of integrating tablets. Lesson preparation requirements specific to the use of tablets (e.g. selecting suitable apps, ensuring access to wireless Internet in the classroom), and the extent to which these would demand additional time and effort, were important considerations guiding teachers' instructional decisions. But perhaps one of the biggest concerns of most teachers relates to the risks of student distraction and its potential negative consequences for student learning and classroom environment. These concerns appear to have increased with the advent of mobile technologies (Wallace, 2011), and may have a negative influence on both teachers' perceptions about its educational value and the way in which they use tablets. For example, Montrieux and colleagues (2014) found that the fear of 'losing control' over

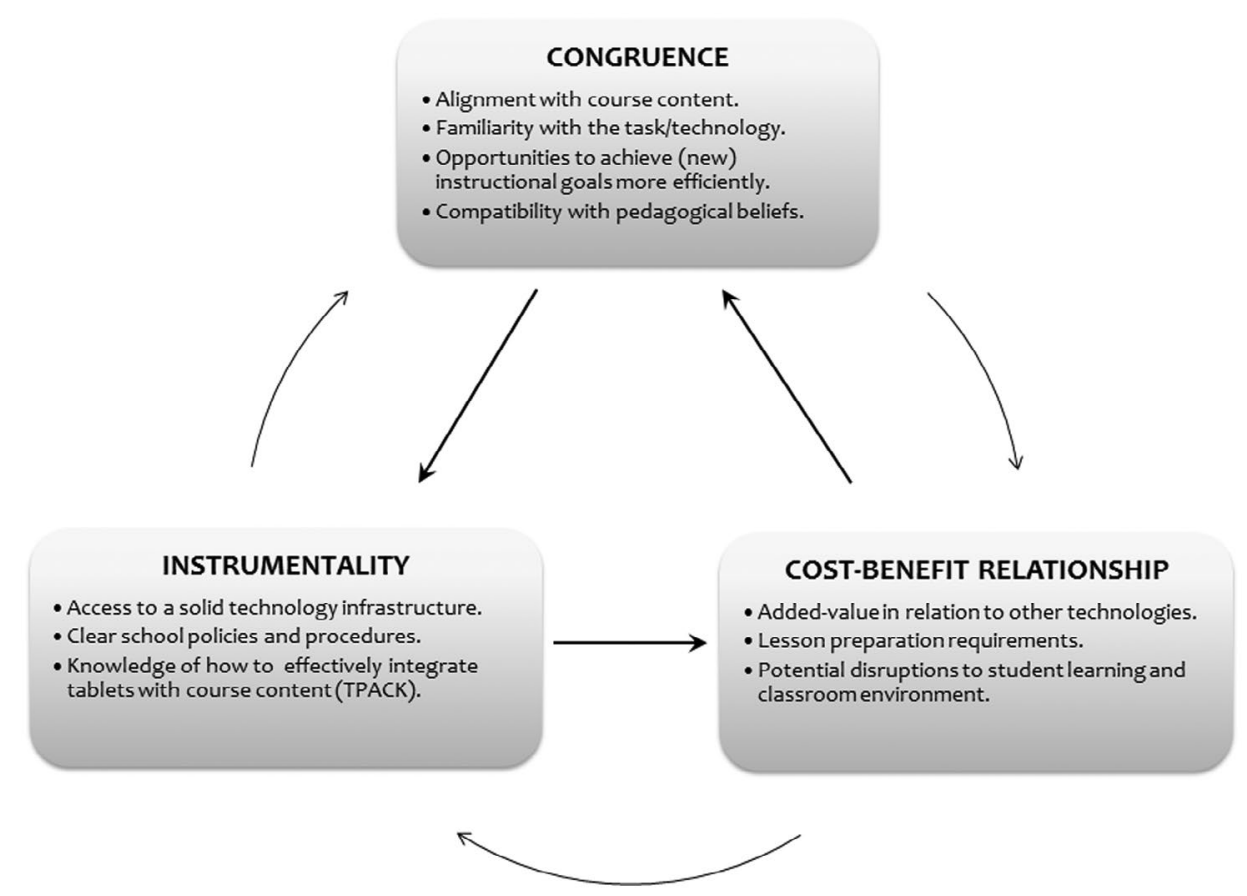

Figure 1. Practical decisions concerning teachers' use of tablets. 
classroom management led teachers to adopt more conservative and teacher-centred approaches. Thus, to support the implementation of tablets, it is of paramount importance to help teachers feel more comfortable with their use, as well as with specific strategies to integrate them in ways that facilitate a positive learning environment.

\section{Instrumentality}

Teachers' decision making was also influenced by the instrumentality dimension of the practicality ethic. Our findings confirm that access to a solid technology infrastructure in terms of wireless Internet, sufficient tablets and suitable educational apps is an important consideration informing teachers' instructional decisions (cf. Ifenthaler \& Schweinbenz, 2013; Montrieux et al., 2014). If teachers are unsure about the extent to which they can count on easy access to these resources, they are unlikely to take on the risk of adopting tablets. Moreover, clear school policies and procedures concerning the educational use of tablets, the acquisition of apps and access to on-site support were identified as important preconditions for sustainable implementation. In this respect, Li (2010) concluded that supportive school structures ensuring access to expertise within the school, as well as a school culture that empowers teachers to take risks and experiment with new ideas and technologies, are decisive for facilitating the implementation of tablets.

Beyond access to a robust technical infrastructure and support structures in the school, teachers underscored the need to further develop their knowledge of how to effectively integrate tablets with course content. Professional development efforts should therefore devote more attention to the development of teachers' subject-specific technological pedagogical content knowledge (TPACK, cf. Mishra \& Koehler, 2006) by bringing teachers in contact with a range of examples that illustrate how the unique characteristics of tablets can be used to support deeper and more engaging student learning across different subject domains.

\section{Limitations and directions for further research}

Overall, the set of 10 criteria identified in the current study provide in-depth insights into teachers' decision-making processes. More specifically, our results suggest that practical concerns constitute a critical element in teachers' decision making, influencing not only teachers' intention to adopt a new technology such as tablets, but also the ways in which they use this technology to support instruction. However, our findings are limited by the short amount of time teachers had to experiment with tablets within the context of this pilot project. Future studies should investigate whether and how teachers' practical concerns change over time as they become more acquainted with the technology - thus moving beyond the initial experiences.

Another limitation of the current study pertains to our specific focus on teachers' practical concerns. While the practicality ethic is a useful framework to understand how teachers may respond to an innovation such as the integration of tablets, it is only one of the multiple aspects influencing teachers' technology integration decisions. Technology adoption is a complex and inherently social process of educational change (Straub, 2009; Tondeur, Kershaw, Vanderlinde, \& van Braak, 2013). Therefore, in order to successfully support the adoption of new technologies such as tablets, cognitive, emotional and contextual concerns must be addressed (Straub, 2009). More research is needed to understand how these different concerns interact with each other and how they can be effectively addressed. For example, future studies could investigate how teachers' disposition to innovate influences their decision to adopt tablets, and the types of concerns guiding the instructional decisions of teachers who are more and less resistant to change.

Understanding the criteria guiding teachers' technology integration decisions is of paramount importance for supporting the successful implementation of growing tablet initiatives around the world. The practicality ethic, despite being an older framework, was here proven to remain relevant and to provide a fresh look at the study of teachers' technology integration decisions. 


\section{Disclosure statement}

No potential conflict of interest was reported by the authors.

\section{Funding}

This study was funded by the Department of Education of the Province of East Flanders.

\section{Notes on contributors}

Natalie Pareja Roblin is a postdoctoral researcher at Pittsburgh University, USA, and a visiting researcher at the Department of Educational Studies of Ghent University. Her research interests include teacher professional development, curriculum innovation and research-practice partnerships in education.

Jo Tondeur is Professor at Vrije Universiteit Brussel and he is also affiliated as a guest professor at Ghent University, Belgium. His research is situated within the field of educational innovations. Most of his research focuses on the integrated use of ICT in pre-service teacher training and compulsory education.

Joke Voogt is a professor at the University of Amsterdam and at Windesheim University of Applied Sciences. She is involved in research on innovative use of ICT in the curriculum and the active involvement of teachers in ICT integration through collaborative design of ICT-enhanced learning environments.

Bram Bruggeman is teacher, teacher educator and school adviser for Provincial Education Flanders. He specialises in ICT and innovation in secondary and adult education. He studied technology-enhanced learning, innovation and change at Sheffield Hallam University, UK.

Griet Mathieu is the head of the teacher education programme at the Centre for Adult Education Het Perspectief.

Johan van Braak is a professor at the Department of Educational Studies at Ghent University. His research interests include ICT integration, educational beliefs and the relation between educational research and practice.

\section{ORCID}

Natalie Pareja Roblin (D) http://orcid.org/0000-0001-9809-9931

Jo Tondeur (iD http://orcid.org/0000-0002-3807-5361

Joke Voogt iD http://orcid.org/0000-0001-5035-9263

Johan van Braak iD http://orcid.org/0000-0002-6989-7886

\section{References}

Anderson, S. E. (1997). Understanding teacher change: Revisiting the concerns based adoption model. Curriculum Inquiry, 27, 331-367.

Boschman, F., McKenney, S., \& Voogt, J. (2014). Understanding decision making in teachers' curriculum design approaches. Educational Technology Research and Development, 62, 393-416.

Calderhead, J. (2011). Stimulated recall: A method for research on teaching. British Journal of Educational Psychology, 51, 211-217.

Chang, J., Lieu, P., Liang, J., Liu, H., \& Wong, S. (2012). A causal model of teacher acceptance of technology. Educational Research and Review, 7(5), 102-110.

Ciampa, K. (2014). Learning in a mobile age: An investigation of student motivation. Journal of Computer Assisted Learning, 30, 82-96.

Connelly, F., Clandinin, D., \& Fang He, M. (1997). Teachers' personal practical knowledge on the professional knowledge landscape. Teaching and Teacher Education, 13, 665-674.

Courtois, C., Montrieux, H., De Grove, F., Raes, A., De Marez, L., \& Schellens, T. (2014). Student acceptance of tablet devices in secondary education: A three-wave longitudinal cross-lagged case study. Computers in Human Behavior, 35, $278-286$.

de Koster, S., Kuiper, E., \& Volman, M. (2012). Concept-guided development of ICT use in 'traditional'and 'innovative' primary schools: What types of ICT use do schools develop? Journal of Computer Assisted Learning, 28, 454-464.

Doyle, W., \& Ponder, G. (1978). The practicality ethic in teacher decision making. Interchange, 8(3), 1-12.

Dündar, H., \& Akçayır, M. (2014). Implementing tablet PCs in schools: Students' attitudes and opinions. Computers in Human Behavior, 32, 40-46. 
El-Gayar, O., Moran, M., \& Hawkes, M. (2011). Students' acceptance of tablet PCs and implications for educational institutions. Educational Technology \& Society, 14(2), 58-70.

Enriquez, A. G. (2010). Enhancing student performance using tablet computers. College Teaching, 58(3), 77-84.

Ertmer, P. (2005). Teacher pedagogical beliefs: The final frontier in our quest for technology integration? Educational Technology Research and Development, 53(4), 25-39.

Fereday, J., \& Muir-Cochrane, E. (2008). Demonstrating rigor using thematic analysis: A hybrid approach of inductive and deductive coding and theme development. International Journal of Qualitative Methods, 5, 80-92.

Fevre, D. (2014). Barriers to implementing pedagogical change: The role of teachers' perceptions of risk. Teaching and Teacher Education, 38, 56-64.

Gómez, M., \& Badia, A. (2016). Exploring the use of educational technology in primary education: Teachers' perception of mobile technology learning impacts and applications' use in the classroom. Computers in Human Behavior, 56, 21-28.

Graham, C. R., Borup, J., \& Sith, N. B. (2012). Using TPACK as a framework to understand teacher candidates' technology integration decisions. Journal of Computer Assisted Learning, 28, 530-546.

Greenhow, C., Dexter, S., \& Hughes, L. (2008). Teacher knowledge about technology integration: An examination of inservice and preservice teachers' instructional decision-making. Science Education International, 19, 9-25.

Hall, G., \& Hord, S. (1987). Change in schools: Facilitating the process. Albany, NY: State University of New York Press.

Harris, J., \& Hofer, M. (2011). Technological Pedagogical Content Knowledge (TPACK) in action: A descriptive study of secondary teachers' curriculum-based, technology-related instructional planning. Journal of Research on Technology in Education, 43, 211-229.

Haßler, B., Major, L., \& Hennessy, S. (2015). Tablet use in schools: A critical review of the evidence for learning outcomes. Journal of Computer Assisted Learning, 32, 139-156.

Herbst, P., Nachlieli, T., \& Chazan, D. (2011). Studying the practical rationality of mathematics teaching: What goes into 'installing' a theorem in geometry? Cognition and Instruction, 29, 218-255.

Ifenthaler, D., \& Schweinbenz, V. (2013). The acceptance of Tablet-PCs in classroom instruction: The teachers' perspectives. Computers in Human Behavior, 29, 525-534.

Janssen, F., Westbroek, H., Doyle, W., \& van Driel, J. (2013). How to make innovations practical. Teachers College Record, 115, 1-44.

Johnson, L., Adams Becker, S., Cummins, M., Estrada, V., Freeman, A., \& Ludgate, H. (2013). NMC Horizon Report: 2013 K-12 edition. Austin, TX: The New Media Consortium.

Lai, H. M., \& Chen, C. P. (2011). Factors influencing secondary school teachers' adoption of teaching blogs. Computers \& Education, 56, 948-960.

Li, S. C. (2010). Social capital, empowerment and educational change: A scenario of permeation of one-to-one technology in school. Journal of Computer Assisted Learning, 26, 284-295.

Li, S. C., Pow, J. W., Wong, E. M., \& Fung, A. C. (2010). Empowering student learning through Tablet PCs: A case study. Education and Information Technologies, 15, 171-180.

Looi, C. K., Wong, L. H., So, H. J., Seow, P., Toh, Y., Chen, W., ... Soloway, E. (2009). Anatomy of a mobilized lesson: Learning my way. Computers \& Education, 53, 1120-1132.

Miles, M., \& Huberman, M. (1994). Qualitative data analysis (2nd ed.). London: Sage.

Mishra, P., \& Koehler, M. (2006). Technological pedagogical content knowledge: A framework for teacher knowledge. Teachers College Record, 108, 1017-1054.

McGrail, E. (2005). Teachers, technology and change: English teachers' perspectives. Journal of Technology and Teacher Education, 13, 5-24.

Montrieux, H., Vanderlinde, R., Courtois, C., Schellens, T., \& De Marez, L. (2014). A qualitative study about the implementation of tablet computers in secondary education: The teachers' role in this process. Procedia-Social and Behavioral Sciences, $112,481-488$.

Moran, M., Hawkes, M., \& El-Gayar, O. (2010). Tablet personal computer integration in higher education: Applying the unified theory of acceptance and use technology model to understand supporting factors. Educational Computing Research, 42, 79-101.

Oncu, S., Delialioglu, O., \& Brown, C. A. (2008). Critical components for technology integration: How do instructors make decisions? Journal of Computers in Mathematics and Science Teaching, 27, 19-46.

Ottenbreit-Leftwich, A., Glazewski, K., Newby, T., \& Ertmer, P. (2010). Teacher value beliefs associated with using technology: Addressing professional and student needs. Computers \& Education, 55, 1321-1335.

Ponder, G., \& Doyle, W. (1977, April). Teacher practicality and curriculum change. An ecological analysis. Paper presented at the annual meeting of the American Educational Research Association, New York, NY.

Straub, E. T. (2009). Understanding technology adoption: Theory and future directions for informal learning. Review of Educational Research, 79, 625-649.

Tamim, R., Borokhovski, E., Pickup, D., \& Bernard, R. (2015). Large-scale, government-supported educational tablet initiatives. Commonwealth of Learning. Retrieved from http://oasis.col.org/handle/11599/809

Tondeur, J., Kershaw, J. H., Vanderlinde, R., \& van Braak, J. (2013). Getting inside the black box of technology integration in education: Teachers' stimulated recall of classroom observations. Australasian Journal of Educational Technology, 29, 434-449. 
Tondeur, J., Pareja Roblin, N., van Braak, J., Fisser, P., \& Voogt, J. (2013, October). Practical examples as a resource for professional development. Know What Works and Why, 38-44.

Twining, P., Raffaghelli, J., Albion, P., \& Knezek, D. (2013). Moving education into the digital age: The contribution of teachers' professional development. Journal of Computer Assisted Learning, 29, 426-437.

Vanderlinde, R., van Braak, J., \& Tondeur, J. (2010). Using an online tool to support school-based ICT policy planning in primary education. Journal of Computer Assisted Learning, 26, 434-447.

Van Houtte, M., \& Stevens, P. (2010). The culture of futility and its impact on study culture in technical/vocational schools in Belgium. Oxford Review of Education, 36, $23-43$.

Venkatesh, V., Morris, M., Davis, G., \& Davis, F. (2003). User acceptance of information technology: Toward a unified view. MIS Quarterly, 27, 425-478.

Wallace, P. (2011). M-learning: Promises, perils, and challenges for K-12 education. New Horizons for Learning, 9, 1-40.

Yin, R. (2003). Case study research: Design and methods (3rd ed.). London: Sage.

Zhao, Y., \& Cziko, G. (2001). Teacher adoption of technology. A perceptual control theory perspective. Journal of Technology and Teacher Education, 9, 5-30.

Zhao, Y., Pugh, K., Sheldon, S., \& Byers, J. L. (2002). Conditions for classroom technology innovations. Teachers College Record, 104, 482-515. 